\title{
Characterization of Eurycoma longifolia (Tongkat Ali) Essential Oils Extracted by Microwave Assisted Extraction
}

\author{
Ghazi Faisal Najmuldeen ${ }^{1}$, Hariitaraan a/l Fatmanathan ${ }^{1}$, Ghasak Ghazi Faisal ${ }^{2 *}$, Zulkafli bin Hassan ${ }^{1}$ \\ ${ }^{1}$ Faculty of Chemical \& Natural Resources Engineering,Universiti Malaysia Pahang, 26300 Gambang, Pahang, Malaysia. \\ ${ }^{2}$ Department of fundamental dental and medical sciences, Kulliyya of Dentistry, International Islamic University Malaysia.
}

\section{ARTICLE INFO \\ Article history: \\ Received on: 28/03/2017 \\ Accepted on: 03/05/2017 \\ Available online: 30/06/2017}

\section{Key words:}

Microwave assisted

extraction, Eurycoma

longifolia root, Eurycoma

longifolia essential oil,

Tongkat Ali.

\begin{abstract}
The main objective of this research is to extract and characterize the essential oils of Eurycoma longifolia jack (Tongkat Ali) root using microwave assisted extraction (MAE) The effect of various process parameters such as extraction time (5 min, $10 \mathrm{~min}, 15 \mathrm{~min}, 20 \mathrm{~min}, 30 \mathrm{~min}$, and $45 \mathrm{~min}$ ), microwave power (200W, 225W, 250W, $275 \mathrm{~W}, 300 \mathrm{~W}$ and $400 \mathrm{~W})$ and raw material to solvent ratio (RMTSR) (1:6, 1:8, 1:10 and 1:12) on the yield and its major constituents were investigated in this study to obtain the optimum conditions for the extraction process. The pure essential oil obtained was characterized using gas chromatography mass spectroscopy (GCMS) techniques. The findings showed that the optimal conditions for the microwave assisted extraction of Eurycoma longifolia are 10 minutes extraction time, $225 \mathrm{~W}$ microwave power and 1:10 for (RMTSR) with the maximum yield percentage of $1.91 \%$.
\end{abstract}

\section{INTRODUCTION}

In this study, the volatiles or essential oils from Eurycoma longifolia or more commonly known as "Tongkat Ali" are extracted using microwave assisted extraction. This plant is mostly found in South-East Asian countries such as Malaysia, Indonesia, Thailand, Myanmar, and Vietnam (Rajeev et al., 2010). The root extracts are used in local traditional medicines for its exclusive antimalarial, anti-pyretic, antiulcer, cytotoxic and aphrodisiac properties (Jagananth, 2000). Microwave assisted extraction of essential oils from plant material has become one of the famous and efficient way to extract out the volatiles. Soxhlet extraction is the most conventional method and widely used in the field of extraction (Vivekananda et al., 2007). However, soxhlet extraction has a major drawback of having longer extraction period, requires larger amount of heat energy for its process and could be a threat to the environment as it

* Corresponding Author

E-mail:drghassak@yahoo.com consumes large amount of organic solvent in the evaporation and concentration of the extract (Zuloaga et al., 1999). Microwave assisted extraction provides the best solution because it requires less consumption of solvent and less extraction time as the process occurs in elevated temperature (Balunkeswar et al., 2015).

Although the thorough statistic demand in international market is imprecise, the price of the dried Eurycoma longifolia roots are expected to be rated in between 20 to 25 US dollars $/ \mathrm{kg}$. Nevertheless, the water extract seemed to have a better market value with 26 US dollars per bottle of 60 capsules (Kaur et al., 2003). The main objective of this study is to extract the essential oils of Eurycoma longifolia's root using Microwave assisted Extraction (MAE) and to characterize the components of essential oils extracted from the roots of Eurycoma longifolia. This study is scoped about investigating the factors (temperature, microwave power, extraction time and solvent volume) affecting the yield and composition extracted from the microwave assisted extraction, separation of solvent and essential oil matrix using rotary evaporator and using the proper tool (GCMS) for the characterization of the components of essential oils. 


\section{MATERIALS AND METHODS}

Methanol of $98.99 \%$ was obtained from UMP Chemical Laboratory store.

The Tongkat Ali root was purchased from $\mathrm{LCH}$ Agriculture, Sungai Petani, Kedah, Malaysia, (the supplier did not indicate whether the root was collected from the wild or cultivated)

\section{Experimental procedure}

The Tongkat Ali root was cut into small pieces $(1-2 \mathrm{~cm})$ to increase the surface area of extraction. Then, the root was dried in the conventional oven to constant weight at $60-80^{\circ} \mathrm{C}$ for 2 hours in the interval of 30 minutes. The dried sample was sealed and stored under room temperature. The microwave assisted extraction was performed using Ethos Microwave Extractor. The weight of sample (Eurycoma longifolia roots) was kept constant at 3 grams throughout the experiment and was soaked with $10 \mathrm{ml}$ of methanol for 10 minutes. This was done to enhance the diffusion of the solvent into the sample and improves the mass transfer of active compounds into the solvent. Three parameters were studied in this study which were time of extraction, microwave power and raw material to solvent ratio. The time of extraction was the first parameter, the RMTSR ratio and microwave power were kept constant at 1:10 $(\mathrm{g} / \mathrm{ml})$ and $250 \mathrm{~W}$ respectively. The time was varied at 5, 10, 15, 20, 30 and 45 minutes. The microwave power was the second parameter, the RMTSR ratio and time of extraction were kept constant at $1: 10(\mathrm{~g} / \mathrm{ml})$ and 10 minutes respectively and the microwave power was varied as $220 \mathrm{~W}, 225 \mathrm{~W}, 250 \mathrm{~W}, 275 \mathrm{~W}$, $300 \mathrm{~W}$ and $400 \mathrm{~W}$. Finally for raw material to solvent ratio, the extraction time and microwave power were kept constant at 10 minutes and $250 \mathrm{~W}$ respectively. The RMTSR was varied as 1:6, $1: 8,1: 10$ and $1: 12(\mathrm{~g} / \mathrm{ml})$.

\section{Separation of the mixture of solvent from extract}

After the extraction process was completed, the mixture of essential oil and solvent were separated from the solid by decantation and filteration. Then, rotary evaporator was used to separate the mixture of essential oil from solvent. After the evaporation of the alcohol was completed, the pure essential oil was transferred into a sample bottle for characterization.

\section{GC-MS Analysis}

The main task for the characterization was to identify the components produced through the MAE in order to compare with the components of the Tongkat Ali root produced through other extraction techinques

The components of the essential oil were quantified using gas chromatography mass spectroscopy (GCMS) of the Agilent model. This instrument functions by separating chemical mixtures (the GC component) and identifying the compositions at a molecular extend (the MS component). It is based on the principle that a mixture will separate into individual components when heat is applied (Neoh et al., 2011). One microliter aliquot of sample was injected at 1:100 split ratio into GCMS system consisting of an Agilent 6890N Gas Chromatograph coupled with an Agilent 5973i Mass Detector and 6890 series auto sampler. The separation was performed using capillary column with helium as the carrier gas. The oven programming was held initially at temperature of $60^{\circ} \mathrm{C}$ and later ramped at $5^{\circ} \mathrm{C} / \mathrm{min}$ to $220^{\circ} \mathrm{C}$ and was held isothermally at this point for 20 minutes (Secilmis Canbay and Bardakc, 2011). As the separated components emerge from the column opening, they diverge into the MS. In order to identify the chemical constituents present in the extracted essential oil, their mass spectra was either compared with those of standard compounds from the National Institute of Standard and Technology (NIST) library data from GC-MS, database (Wiley/ NBS library) or with published mass spectra (Adams., 2001). Close similarity in retention time of the compound from both techniques were observed when the components were quantified.

\section{Statistical analysis}

Analysis of variance (ANOVA) was used to test the effects of extraction time, microwave power and raw material to solvent ratio (RMTSR) on the yield of essential oil extracted. The results of the two replicates for all the analysis done were expressed as mean and ANOVA. Significance is accepted at $\mathrm{P}<0.5$.

\section{RESULTS AND DISCUSSION}

\section{Effect of extraction time}

The percentage yield of the Tongkat Ali essential oil was calculated at a constant microwave power of $250 \mathrm{~W}$, and at raw material to solvent ratio of 1:10 based on average values obtained. The yield percentage was calculated using Equation 1.

Yield Percentage, $\%=\frac{\text { Essential oil weight after evaporation }}{\text { Raw material weight }} \times 100 \quad$ Eq.1

Figure 1 illustrates the percentage yield of essential oil extracted from Eurycoma longifolia (Tongkat Ali) at different extraction time at a constant microwave power of $250 \mathrm{~W}$, and at raw material to solvent ratio of 1:10. From the table and graph, it can be clearly seen that the amount of yield increases as the extraction time was increased from $5 \mathrm{~min}$ to $10 \mathrm{~min}$. The yield obtained at 5 and $10 \mathrm{~min}$ are $1.5 \%$, and $1.83 \%$ respectively. Apparently microwave assisted extraction was able to produce the highest yield of $1.83 \%$ when the extraction time is $10 \mathrm{~min}$. Nevertheless, as the extraction time was increased beyond $10 \mathrm{~min}$, the yield can be seen to be reduced. The same observation was reported for microwave assisted extraction of pectin from waste Citrullus lanatus fruit rinds (Prakash Maran et al., 2014). The initial increase in extraction yield supports the fact that the more the time the more the thermal accumulation within the solvent (methanol) due to the absorption of microwave energy enhanced the dissolution process of essential oil into the solvent (Maran et al., 2013). The decrease in yield after 10 min extraction time could 
however be related with the possible degradation of the plant material as the extraction time increases (Chen et al., 2007).

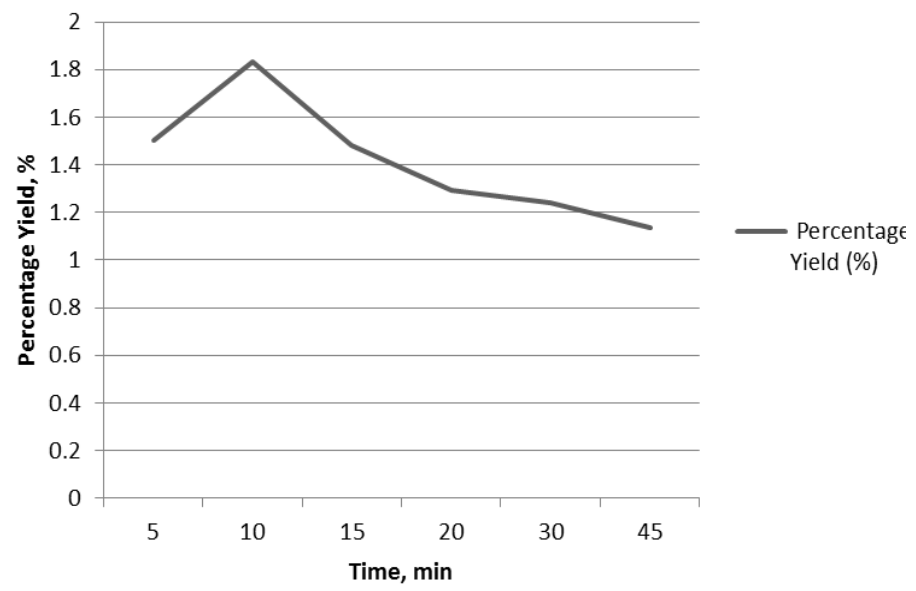

Fig. 1: Percentage Yield against Extraction Time.

\section{Effect of microwave Power}

The percentage yield of the Tongkat Ali essential oil is calculated at a constant extraction time of $10 \mathrm{~min}$, and at raw material to solvent ratio of $1: 10$ based on average values obtained. The percentage yield was calculated using Equation 1.

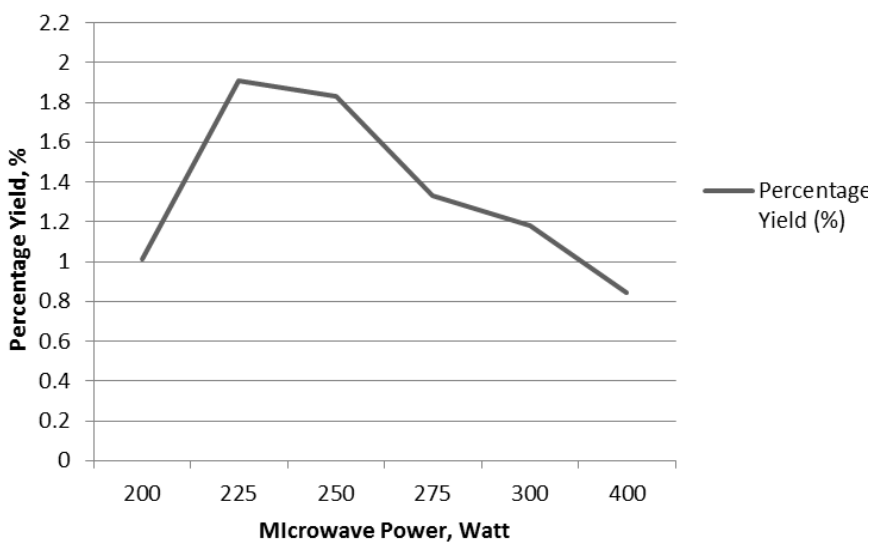

Fig. 2: Percentage Yield against Microwave Power.

Figure 2 illustrates the percentage yield of essential oil extracted from Eurycoma longifolia (Tongkat Ali) at different microwave power at a constant extraction time of $10 \mathrm{~min}$, and at raw material to solvent ratio of 1:10. Six different microwave power levels were used in the extraction which were $200 \mathrm{~W}, 225$ W, 250 W, 275 W, 300 W, 400 W. From Figure 2, it can be seen that when the microwave power increases, the percentage yield of extracted Tongkat Ali essential oil increased until 225W and started to decrease from $250 \mathrm{~W}$ until $400 \mathrm{~W}$. It is observed that the highest yield of $1.91 \%$ which was obtained when Tongkat Ali essential oil extracted was conducted at $225 \mathrm{~W}$ for a period of 10 min. This is because higher microwave power would supply more energy to the immersed Tongkat Ali, produce rapid generation of heat, and subsequent formation of higher pressure gradient inside of the Tongkat Ali and methanol (solvent) such that the extraction is enhanced (Rezvanpanah et al., 2008). However, for the higher microwave power, the yield of Tongkat Ali essential oil decreases. There is the possibility of a negative effect from higher microwave power, which might tend to overheat the product by elevating the temperature too high, leading to the compound breakdown or product damage (Ma et al., 2009).

\section{Effect of raw material to solvent ratio (RMTSR)}

The Tongkat Ali essential oil was calculated at a constant extraction time of $10 \mathrm{~min}$, and microwave power of $250 \mathrm{~W}$ based on average values obtained. The percentage yield is calculated according to Equation 1. Figure 3 illustrates the percentage yield of essential oil extracted from Eurycoma longifolia (Tongkat Ali) at different raw material to solvent ratio at a constant extraction time of $10 \mathrm{~min}$, and microwave power of $250 \mathrm{~W}$. Four different RMTSR were used in the extraction which are 1:6, 1:8, 1:10 and 1:12. From Figure 4.3 it can be clearly seen that the Tongkat Ali essential oil extraction increases as the RMTSR increases until it reached the maximum yield at $1: 10$ which is $1.83 \%$. This is because the driving force during mass transfer within the solid is considered to be the concentration gradient, which is greater when the high solvent-to-solid ratio are used, resulting in an increase of the diffusion rate ( Khanal et al., 2006). However at RMTSR of $1: 12$ the yield started to decrease because the raw material could not take up more solvent than the equilibrium point resulting with low mass transfer and diffusivity (Cacace and Mazza 2003).

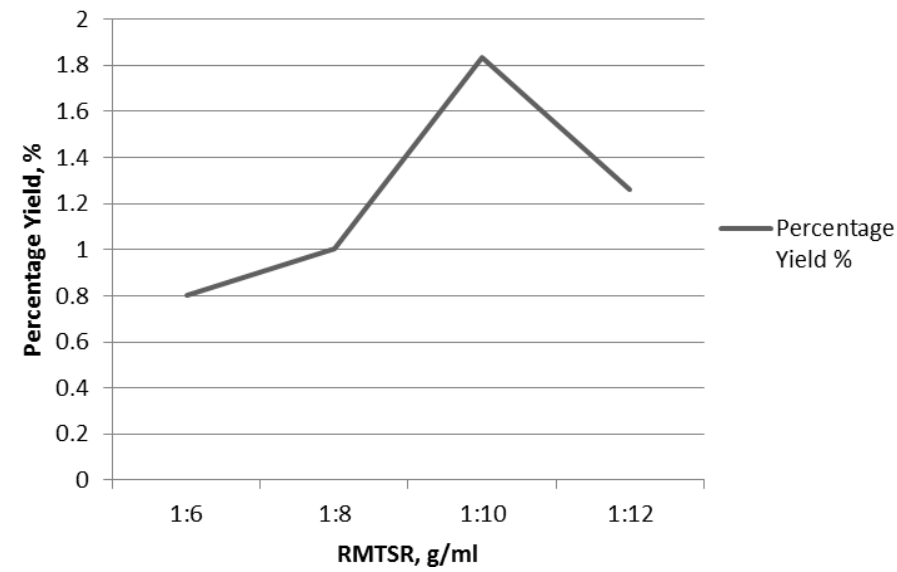

Fig. 3: Percentage Yield against RMTSR

\section{GCMS Analysis}

The Tongkat Ali essential oil obtained from the parameters of extraction time, microwave power and weight ratio were analysed using gas chromatography and mass spectroscopy in order to compare the extracted essential oil compositions with the commercial Tongkat Ali essential oil. Figure 4, Figure 5 and Figure 6 shows the peaks found in GCMS for the extraction time of 5 minutes, microwave power of $200 \mathrm{~W}$ and raw material to solvent ratio of Tongkat Ali : $\mathrm{MeOH}$ at 1:6, respectively. Table 4 , Table 5 and Table 6 summarises the components of essential oil 
found in each of the samples for all the three parameters investigated in this study.

Table 1, 2 and 3 reveals the results and the components identified through GCMS. The components in the Tongkat Ali essential oil were detected at the retention time in the range from 1 to 20 minutes. The solvent, methanol was detected first at retention time of 1.922. There were 9 components detected in total. Generally, the components such as (3,5-Dimethoxy-4hydroxyphenylacetic acid, Carbazole, Acetic acid, Butyrolactone and 3-methylbutanoic acid) were found in each and every samples of the parameters. The largest peak found is 3,5-Dimethoxy-4hydroxyphenylacetic acid with retention time of 9.199. Some components that were detected at retention time of $10.133,12.693$ and 18.263 and were identified as (Nonanal, 2-Methylhexanol, 2(5H)-Furanone) were the least found components.

\section{Statistical analysis}

Based on the statistical analysis done using single factor ANOVA (analysis of variance), the $\mathrm{p}$ value obtained for the extracted essential oil (g) based on extraction time, microwave power and RMTSR are 0.001469, 0.000057 and 0.001549 respectively. Thus, all the results are valid and significant at $\mathrm{p}<0.5$.

Table 1: Components Identified in Tongkat Ali Extract at Extraction Time Parameter.

\begin{tabular}{|c|c|c|c|c|c|c|c|c|}
\hline \multirow{3}{*}{ No } & \multirow{3}{*}{ Retention Time } & \multirow{3}{*}{ Compound } & \multicolumn{6}{|c|}{ Relative Peak (\%) } \\
\hline & & & \multicolumn{6}{|c|}{ Extraction Time (min) } \\
\hline & & & 5 & 10 & 15 & 20 & 30 & 45 \\
\hline 1 & 1.922 & Methanol (Solvent) & 20.59 & 47.94 & 29.03 & 18.46 & 9.41 & 15.19 \\
\hline 2 & 6.612 & 2-Hexadecanol & $\sim$ & 2.40 & 1.68 & 5.10 & $\sim$ & 0.55 \\
\hline 3 & 9.199 & 3,5-Dimethoxy-4-hydroxyphenylacetic acid & 19.38 & 7.59 & 3.24 & 9.88 & 17.76 & 18.16 \\
\hline 4 & 9.405 & Carbazole & 14.87 & 3.69 & 0.81 & 6.46 & 11.76 & 9.69 \\
\hline 5 & 10.133 & Nonanal & $\sim$ & $\sim$ & $\sim$ & 11.15 & $\sim$ & $\sim$ \\
\hline 6 & 11.803 & Acetic acid & 26.84 & 6.50 & 3.88 & 7.93 & 17.05 & 9.40 \\
\hline 7 & 12.693 & 2-Methylhexanol & $\sim$ & $\sim$ & $\sim$ & 2.97 & $\sim$ & $\sim$ \\
\hline 8 & 15.931 & Butyrolactone & 13.18 & 2.50 & 1.92 & 3.00 & 8.20 & 3.16 \\
\hline 9 & 17.429 & 3-methylbutanoic acid & 5.14 & 1.00 & 1.05 & 1.35 & 3.62 & 1.33 \\
\hline 10 & 18.263 & 2(5H)-Furanone & $\sim$ & $\sim$ & 13.18 & $\sim$ & 1.10 & $\sim$ \\
\hline
\end{tabular}

(Source: Shafiqul Islam et al., 2006 and Purwantiningsih et al., 2011).

Table 2: Components Identified in Tongkat Ali Extract at Microwave Power Parameter.

\begin{tabular}{|c|c|c|c|c|c|c|c|c|}
\hline \multirow{3}{*}{ No } & \multirow{3}{*}{ Retention Time } & \multirow{3}{*}{ Compound } & \multicolumn{6}{|c|}{ Relative Peak (\%) } \\
\hline & & & \multicolumn{6}{|c|}{ Microwave Power (Watt) } \\
\hline & & & 200 & 225 & 250 & 275 & 300 & 400 \\
\hline 1 & 1.922 & Methanol (Solvent) & 51.20 & 39.97 & 47.94 & 38.16 & 38.00 & 52.53 \\
\hline 2 & 6.612 & 2-Hexadecanol & $\sim$ & $\sim$ & 2.40 & $\sim$ & $\sim$ & $\sim$ \\
\hline 3 & 9.199 & 3,5-Dimethoxy-4-hydroxyphenylacetic acid & 6.15 & 6.99 & 7.59 & 16.09 & 3.67 & 7.63 \\
\hline 4 & 9.405 & Carbazole & 3.60 & 6.06 & 3.69 & 8.79 & 3.17 & 5.32 \\
\hline 5 & 10.133 & Nonanal & $\sim$ & $\sim$ & $\sim$ & $\sim$ & 1.01 & $\sim$ \\
\hline 6 & 11.803 & Acetic acid & 4.41 & 5.11 & 6.50 & 23.97 & 6.74 & 3.19 \\
\hline 7 & 12.693 & 2-Methylhexanol & $\sim$ & $\sim$ & $\sim$ & $\sim$ & $\sim$ & $\sim$ \\
\hline 8 & 15.931 & Butyrolactone & 1.82 & 1.65 & 2.50 & 8.77 & 2.37 & 1.76 \\
\hline 9 & 17.429 & 3-methylbutanoic acid & 1.00 & 1.02 & 1.00 & 4.21 & 3.07 & 1.09 \\
\hline 10 & 18.263 & 2(5H)-Furanone & $\sim$ & $\sim$ & $\sim$ & $\sim$ & $\sim$ & $\sim$ \\
\hline
\end{tabular}

(Source: Shafiqul Islam et al., 2006 and Purwantiningsih et al., 2011).

Table 3: Components Identified in Tongkat Ali Extract at RMTSR Parameter.

\begin{tabular}{|c|c|c|c|c|c|c|}
\hline \multirow{3}{*}{ No } & \multirow{3}{*}{ Retention Time } & \multirow{3}{*}{ Compound } & \multirow{2}{*}{\multicolumn{4}{|c|}{$\begin{array}{c}\text { Relative Peak (\%) } \\
\text { RMTSR }(\mathrm{g} / \mathrm{ml})\end{array}$}} \\
\hline & & & & & & \\
\hline & & & $1: 6$ & $1: 8$ & $1: 10$ & $1: 12$ \\
\hline 1 & 1.922 & Methanol (Solvent) & 41.59 & 4.25 & 47.94 & 4.13 \\
\hline 2 & 6.612 & 2-Hexadecanol & $\sim$ & $\sim$ & 2.40 & 0.93 \\
\hline 3 & 9.199 & 3,5-Dimethoxy-4-hydroxyphenylacetic acid & 8.83 & 18.04 & 7.59 & 4.61 \\
\hline 4 & 9.405 & Carbazole & 4.80 & 9.67 & 3.69 & 2.52 \\
\hline 5 & 10.133 & Nonanal & $\sim$ & 0.31 & $\sim$ & 10.48 \\
\hline 6 & 11.803 & Acetic acid & 7.98 & 24.56 & 6.50 & 3.58 \\
\hline 7 & 12.693 & 2-Methylhexanol & $\sim$ & $\sim$ & $\sim$ & 32.57 \\
\hline 8 & 15.931 & Butyrolactone & 2.86 & 12.99 & 2.50 & 0.96 \\
\hline 9 & 17.429 & 3-methylbutanoic acid & 1.11 & 6.07 & 1.00 & 0.42 \\
\hline 10 & 18.263 & 2(5H)-Furanone & $\sim$ & 2.31 & $\sim$ & $\sim$ \\
\hline
\end{tabular}

(Source: Shafiqul Islam et al., 2006 and Purwantiningsih et al., 2011). 


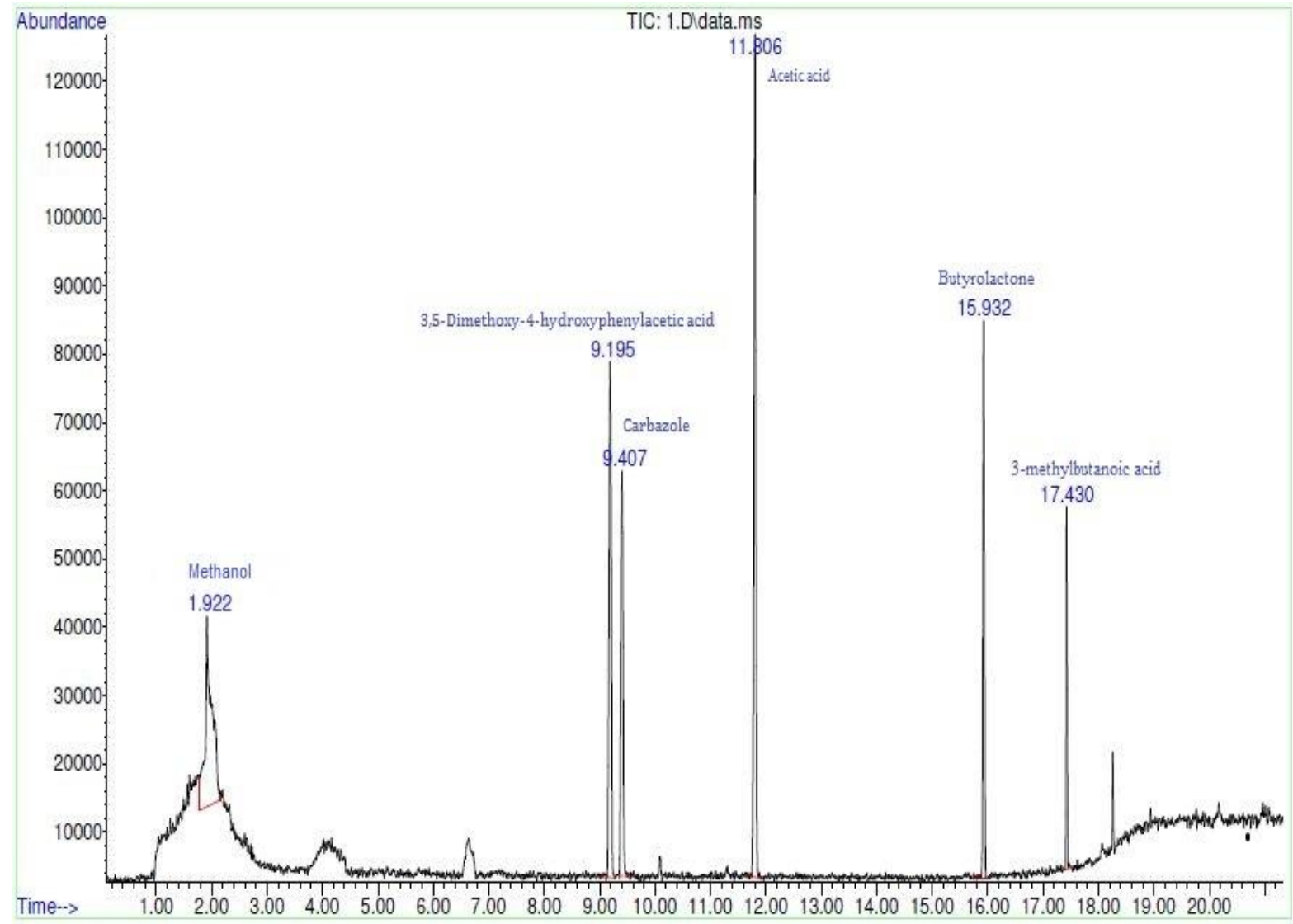

Fig. 4: GCMS of 5 minutes Extraction time.

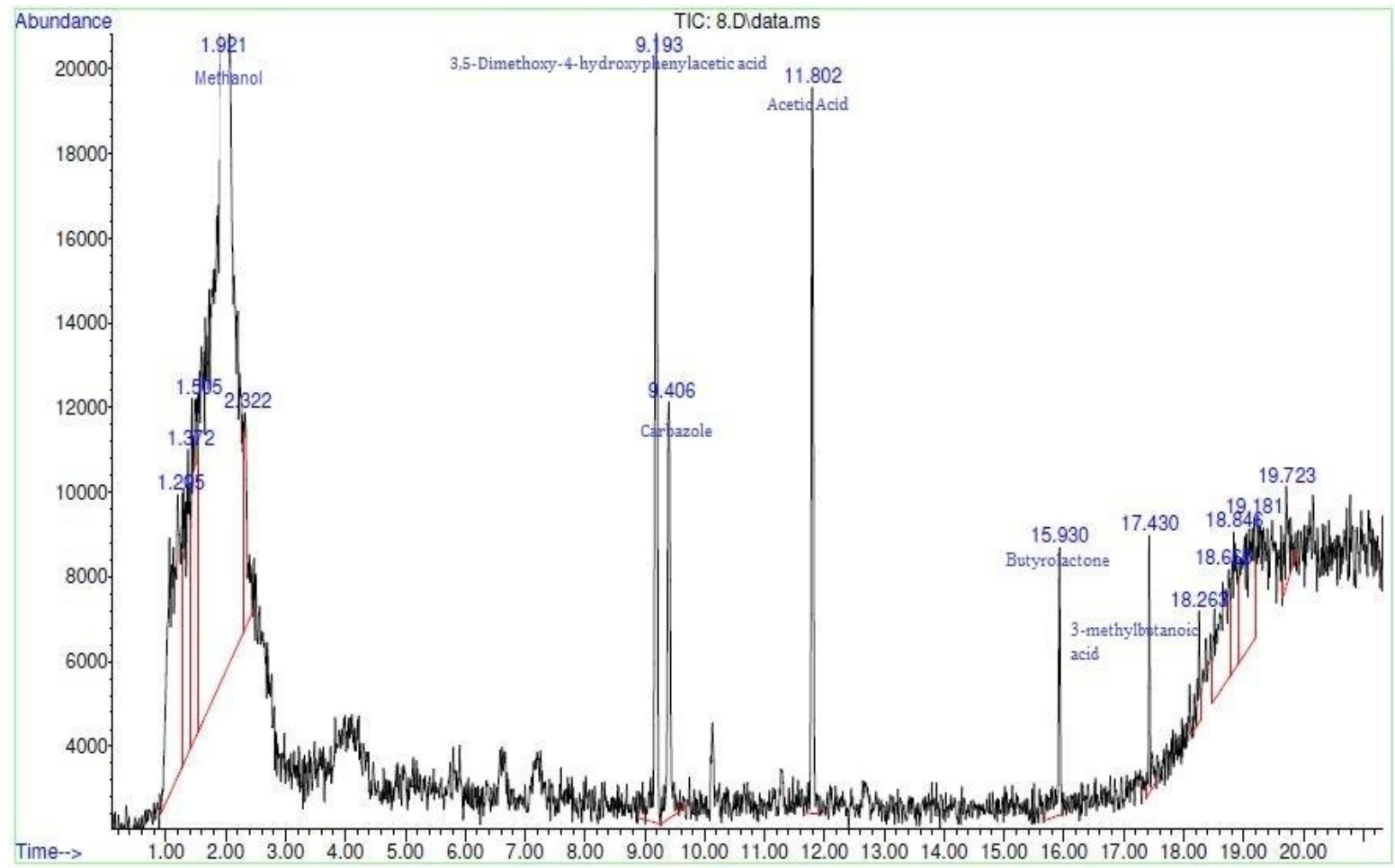

Fig. 5: GCMS of extract using Microwave Power of 200W. 


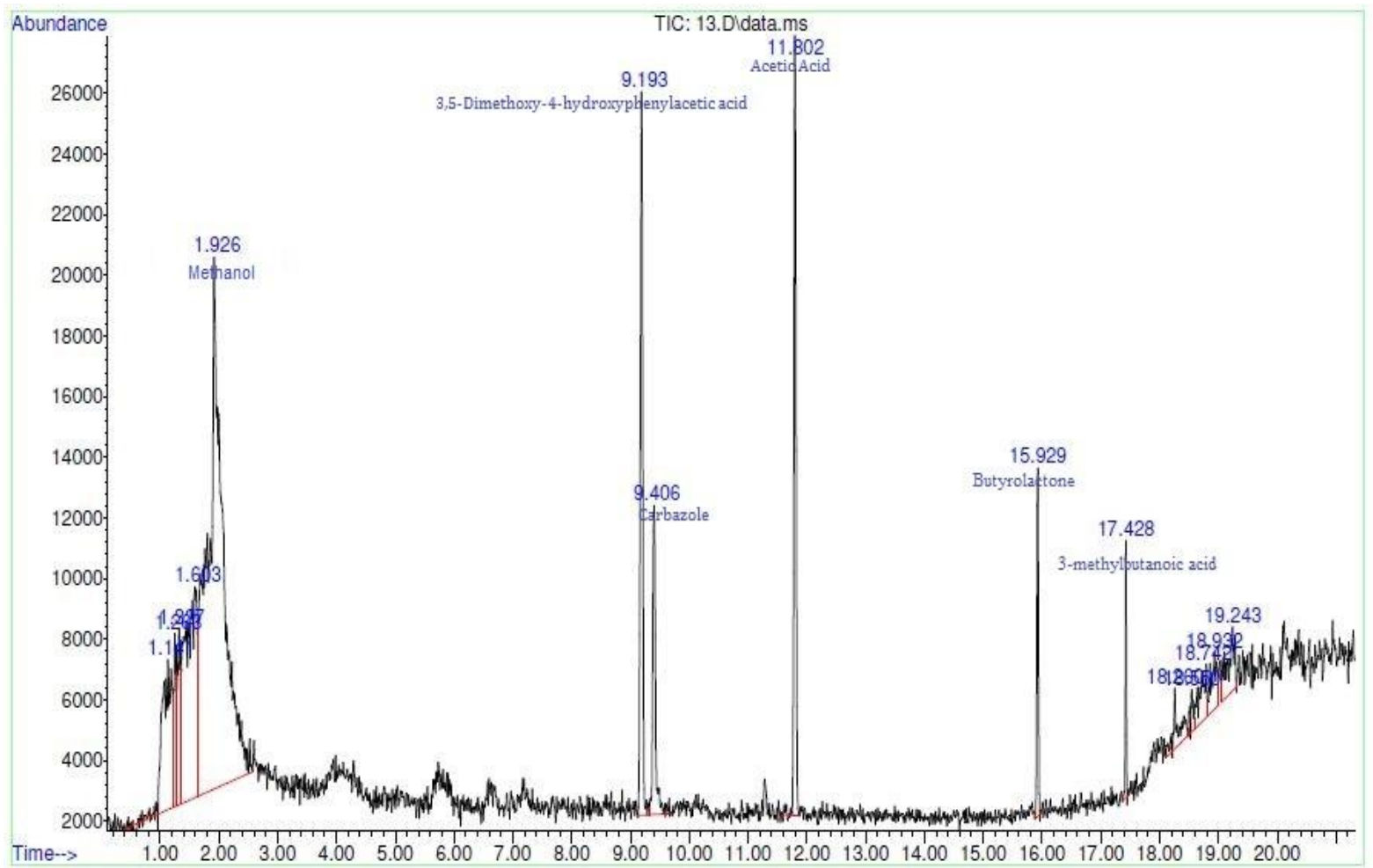

Fig. 6: GCMS extract weigh to solvent of 1:6.

\section{CONCLUSION}

The essential oil of Eurycoma longifolia has been extracted using Microwave assisted Extraction (MAE) and the components of the extracted essential oil were characterized and quantified using GCMS, showing similarities to previous publication results .Three parameters were investigated in this study namely extraction time, microwave power and raw material to solvent ratio (RMTSR). The optimum conditions for the microwave assisted extraction of Eurycoma longifolia are 10 minutes for extraction time, $225 \mathrm{~W}$ for microwave power and 1:10 for RMTSR with the maximum yield percentage of $1.83 \%, 1.91 \%$ and $1.83 \%$ respectively.

\section{ACKNOWLEDGMENTS}

Financial support and sponsorship: The authors wishes to thank University Malaysia Pahang and International Islamic University Malaysia for providing research funding.

Conflict of Interests: There are no conflicts of interest.

\section{REFERENCES}

A.K.M. Shafiqul Islam, Z. Ismail, B. Saad, A.R. Othmanc, M.N. Ahmadd, A.Y.Md. Shakaff. .Correlation studies between electronic nose response and headspace volatiles of Eurycoma longifolia extracts. Sensors and Actuators B: Chemical. 2006;120(1):245-51.
Balunkeswar Nayak, Farid Dahmoune, Kamal Moussi, Hocine Remini, Sofiane Dairi, Omar Aoun, Madani Khodir. Comparison of microwave, ultrasound and accelerated-assisted solvent extraction for recovery of polyphenols from Citrus sinensis peels. Food Chemistry,2015; 187:507-516.

Cacace, J.E., Mazza, G. Mass transfer process during extraction of phenolic compounds form milled berries. Journal of Food Engineering, 2003;59: 379-389

Chen Y, Xie M.Y, and Gong, X.F. Microwave-assisted extraction used for the isolationof total triterpenoid saponins from Ganoderma atrum.Journal of Food Engineering, 2007;81(1):162-170.

Jaganath IB, Ng LT. Herbs. The Green Pharmacy of Malaysia. Kuala Lumpur, Vinpress and Malaysia Agricultural Research and Development Institute. 2000:95-9.

Kaur I, Kumaresan S, Sarmidi MR. A study into the effect of laboratory scale processing parameters and scale up on Eurycoma longifolia water extract yield. InProceedings of the 17th Symposium of Malaysian Chemical Engineers 2003 Dec 29 (pp. 294-299).

Khanal SK, Isik H, Sung S, Van Leeuwen J. Ultrasound pretreatment of waste activated sludge: evaluation of sludge disintegration and aerobic digestibility. InProceedings of IWA World Water Congress and Exhibition 2006 Sep 10 (pp. 10-14). Beijing, China: September.

Ma, W., Lu, Y., Dai, X., Liu, R., Hu, R., Pan, Y. Determination of anti-tumor constitute mollugin from traditional Chinese medicine Rubia cordifolia: Comparative study of classical and microwave extraction techniques. Separation Science and Technology,2009;44(4): 995-1006.

Maran JP, Sivakumar V, Thirgananasambandham K, Sridhar R. Optimization of microwave assisted extraction of pectin from orange peel. Car-bohydrate Polymers. 2013;97:703-709.

Maran JP, Sivakumar V, Thirugnanasambandham K, Sridhar R. Microwave assisted extraction of pectin from waste Citrullus lanatus fruit rinds. Carbohydrate polymers. 2014 Jan 30;101:786-91. 
Neoh BK, Thang YM, Zain MZ, Junaidi A. Palm pressed fibre oil: A new opportunity for premium hardstock?. Int. Food Res. J. 2011 May 1;18(2):769-73.

Purwantiningsih HA, Chan KL. Free radical scavenging activity of the standardized ethanolic extract of Eurycoma longifolia (TAF-273). Int J Pharm Pharm Sci. 2011;3:343-7.

R. P. Adams. Identification of essential oils by gas chromatography quadrupole mass spectrometry.Allured Publishing Corporation, Carol Stream, 2001. USA.

Rajeev Bhat, A.A. Karim. Tongkat Ali (Eurycoma longifolia Jack): A review on its ethnobotany and pharmacological importance. Fitoterapia, 2010;81: 669-679.

Rezvanpanah S, Rezaei K, Razavi, S. H, and MoiniS. Use of Microwave assisted Hydrodistillation to Extract the Essential Oils from Satureja hortensis and Satureja montana. Food science and technology research., 2008;14(3): 311-314.

Seçilmiş Canbay H, and Bardakç B. Determination of Fatty Acid, C, H, N and Trace Element Composition in Grape Seed by GC/MS, FTIR, Elemental Analyzer and ICP/OES. Journal Of Science (E-Journal). 2011; 6 (2): 140-148, 142.
Vivekananda Mandal, Yogesh Mohan, S. Hemalatha. Review Article Microwave Assisted Extraction - An Innovative and Promising Extraction Tool for Medicinal Plant Research, 2007; Vol 1, Issue 1.

Zuloaga $\mathrm{O}$, Etxebarria N, Fernández LA, Madariaga JM. Optimisation and comparison of microwave-assisted extraction and Soxhlet extraction for the determination of polychlorinated biphenyls in soil samples using an experimental design approach. Talanta. 1999 Sep 13;50(2):345-57.

\section{How to cite this article:}

Najmuldeen GF, Fatmanathan HA, Faisal GG, Hassan ZB. Characterization of Eurycoma longifolia (Tongkat Ali) Essential Oils Extracted by Microwave Assisted Extraction., J App Pharm Sci, 2017; 7 (06): 062-068. 